\title{
Leigh syndrome in individuals bearing m.9185T $>$ C MTATP6 variant. Is hyperventilation a factor which starts its development?
}

\author{
Dorota Piekutowska-Abramczuk ${ }^{1}$ (D) - Rafal Rutyna ${ }^{2}$ - Elżbieta Czyżyk ${ }^{3}$. \\ Elżbieta Jurkiewicz $^{4}$ - Katarzyna Iwanicka-Pronicka ${ }^{5}$ - Dariusz Rokicki ${ }^{6}$. \\ Sylwia Stachowicz ${ }^{7}$. Joanna Strzemecka ${ }^{8,9}$. Wieslaw Guz ${ }^{10,11}$ - Michal Gawroński ${ }^{12}$. \\ Aneta Kosierb $^{12}$ - Joanna Ligas ${ }^{12}$ - Mateusz Puchala ${ }^{12}$ - Anna Drelich-Zbroja ${ }^{13}$. \\ Malgorzata Bednarska-Makaruk ${ }^{14}$ - Wojciech Dąbrowski ${ }^{2}$. Elżbieta Ciara ${ }^{1}$. \\ Janusz B. Książyk ${ }^{6} \cdot$ Ewa Pronicka $^{1,6}$
}

Received: 17 March 2017 / Accepted: 4 October 2017 / Published online: 7 November 2017

(C) The Author(s) 2017, Corrected publication November/2017. This article is an open access publication

\begin{abstract}
Leigh syndrome (LS), subacute necrotizing encephalomyelopathy is caused by various genetic defects, including m.9185T>C MTATP6 variant. Mechanism of LS development remains unknown. We report on the acid-base status of three patients with m.9185T $>$ C related LS. At the onset,
\end{abstract}

Electronic supplementary material The online version of this article (https://doi.org/10.1007/s11011-017-0122-1) contains supplementary material, which is available to authorized users.

Dorota Piekutowska-Abramczuk

d.abramczuk@czd.pl

Ewa Pronicka

e.pronicka@ipczd.pl

Rafał Rutyna

rutynapraca@gmail.com

Elżbieta Czyżyk

el.czyzyk@wp.pl

Elżbieta Jurkiewicz

e.jurkiewicz@ipczd.pl

Katarzyna Iwanicka-Pronicka

katarzyna.iwanicka@yahoo.com

Dariusz Rokicki

d.rokicki@czd.pl

Sylwia Stachowicz

sstachowicz@wp.pl

Joanna Strzemecka

joannastrzemecka@wp.pl

Wiesław Guz

wguz@op.pl

Michał Gawroński

mich.gawronski@gmail.com it showed respiratory alkalosis, reflecting excessive respiration effort (hyperventilation with low $\mathrm{pCO}_{2}$ ). In patient 1 , the deterioration occurred in temporal relation to passive oxygen therapy. To the contrary, on the recovery, she demonstrated a relatively low respiratory drive, suggesting that a
Aneta Kosierb

annkos100@gmail.com

Joanna Ligas

asialigas@buziaczek.pl

Mateusz Puchala

puchala68@gmail.com

Anna Drelich-Zbroja

zbroanna@interia.pl

Małgorzata Bednarska-Makaruk

makaruk@ipin.edu.pl

Wojciech Dąbrowski

w.dabrowski5@gmail.com

Elżbieta Ciara

e.ciara@czd.pl

Janusz B. Książyk

j.ksiazyk@czd.pl

1 Department of Medical Genetics, The Children's Memorial Health Institute, Aleja Dzieci Polskich 20, 04-730 Warsaw, Poland

2 Chair and Department of Anaesthesiology and Intensive Therapy, Medical University of Lublin, Lublin, Poland

3 Clinical Department of Child Neurology, Clinical Central Hospital No 2 in Rzeszow, Rzeszow, Poland 
"hypoventilation" might be beneficial for m.9185T $>\mathrm{C}$ carriers. As long as circumstances of the development of LS have not been fully explained, we recommend to counteract hyperventilation and carefully dose oxygen in patients with m.9185T $>$ C related LS.

Keywords Leigh syndrome $\cdot$ m.9185T $>$ C variant $\cdot$ MTATP6 . Hypocapnia $\cdot$ Respiratory alkalosis $\cdot$ Oxygen therapy

\section{Introduction}

Leigh syndrome (LS) is a progressive neurodegenerative disorder of genetic origin diagnosed on autopsy and/or with magnetic resonance imaging (MRI). It may be related to changes in over 75 various genes (Lake et al. 2016). One of recurrent causes of the late onset LS is $\mathrm{m} .9185 \mathrm{~T}>\mathrm{C}$ variant of the MTATP6 gene (Moslemi et al. 2005). The reason for sudden development of LS in m.9185T $>$ C carriers is not known, but an infection was underlined as a trigger in some reports (Pitceathly et al. 2012, Saneto and Singh 2010, Castagna et al. 2007). We assume that hypocapnia and respiratory (hypocapnic) alkalosis (Pronicka and Halikowski 1984; Pronicka 2017), reflecting hyperventilation, may contribute to LS occurrence. We established this on an empirical basis in three $\mathrm{m} .9185 \mathrm{~T}>\mathrm{C}$ carriers.

$\overline{\text { Department }}$ of Radiology, The Children's Memorial Health Institute, Warsaw, Poland

5 Department of Audiology and Phoniatrics, The Children's Memorial Health Institute, Warsaw, Poland

6 Department of Pediatrics, Nutrition and Metabolic Diseases, The Children's Memorial Health Institute, Warsaw, Poland

7 Department of Neurology, Public Independent Clinic Hospital No 4 in Lublin, Lublin, Poland

8 Department of Orthopaedics and Rehabilitation, Public Independent Clinic Hospital No 4 in Lublin, Lublin, Poland

9 Institute of Health Sciences, Pope John Paul II State School of Higher Education, Biała Podlaska, Poland

10 Department of Electroradiology, Institute of Nursing and Health Sciences, Faculty of Medicine, University of Rzeszow, Rzeszów, Poland

11 Clinical Department of Radiology, Clinical Central Hospital No 2, Rzeszow, Poland

12 Student Academic Club at The Chair and Department of Anaesthesiology and Intensive Therapy, II Faculty of Medicine with English Language Division, Medical University of Lublin, Lublin, Poland

13 Department of Interventional Radiology and Neuroradiology Medical University of Lublin, Lublin, Poland

14 Department of Genetics, Institute of Psychiatry and Neurology, Warsaw, Poland

\section{Material and methods}

\section{Patients with Leigh syndrome}

Three patients with late onset LS were studied. There were two unrelated children and the mother of one of them bearing the MTATP6 m.9185T >C variant, who developed LS at the age of 5,9 and 33 years, respectively. Additionally, four m.9185T $>C$ carriers without LS features, who were identified by cascade studies of both families were included in this study.

Details of the clinical course are presented in supplementary materials (Tables $1-3$ ).

All procedures performed in the study were in accordance with the ethical standards of the CMHI bioethical committee and with the 1964 Helsinki declaration and its later amendments or comparable ethical standards.

Informed consent was obtained from all individual participants included in the study.

\section{Family 1, patient 1}

A 33 year-old woman, was admitted to the neurological ward because of exacerbation preceded by infection symptoms. Initially, a congenital polyneuropathy was diagnosed. In few days the patient developed severe respiratory problems. Late onset LS was diagnosed by MRI (Fig. 1, line A) and carriage of MTATP6 m.9185T >C variant was established following the diagnosis in her daughter (patient 2). The patient needed artificial respiratory support and was hospitalized for 5 months.

On the follow-up examination, her clinical status was assessed as stabile. MRI performed after 11 months showed a partial regression of LS changes (Fig. 1, line B). Over a year since the LS onset, the patient was wheelchair depending, with good mental communication.

\section{Family 1, patient 2}

The daughter of patient 1, developed LS at the age of 5 (Fig. 1, line $\mathrm{C}$ ). The only abnormality noted in the early childhood was a little sluggish speech. The course of LS was mild. Her clinical condition spontaneously returned to normal, she started primary school in the normal time (7 years). Control brain MRI performed at the age of 9 showed maintenance of previously seen LS changes, although in a less extent (Fig. 1, line D). At this time, molecular diagnostics revealed the MTATP6 m.9185T >C pathogenic variant. Ascertain of the cause of LS in patient 2 coincided with the development of the similar disease in her mother (patient 1).

\section{Family 2, patient 3}

A 9 year-old boy was admitted to a regional hospital due to acute onset of imbalance, severe muscle weakness, 

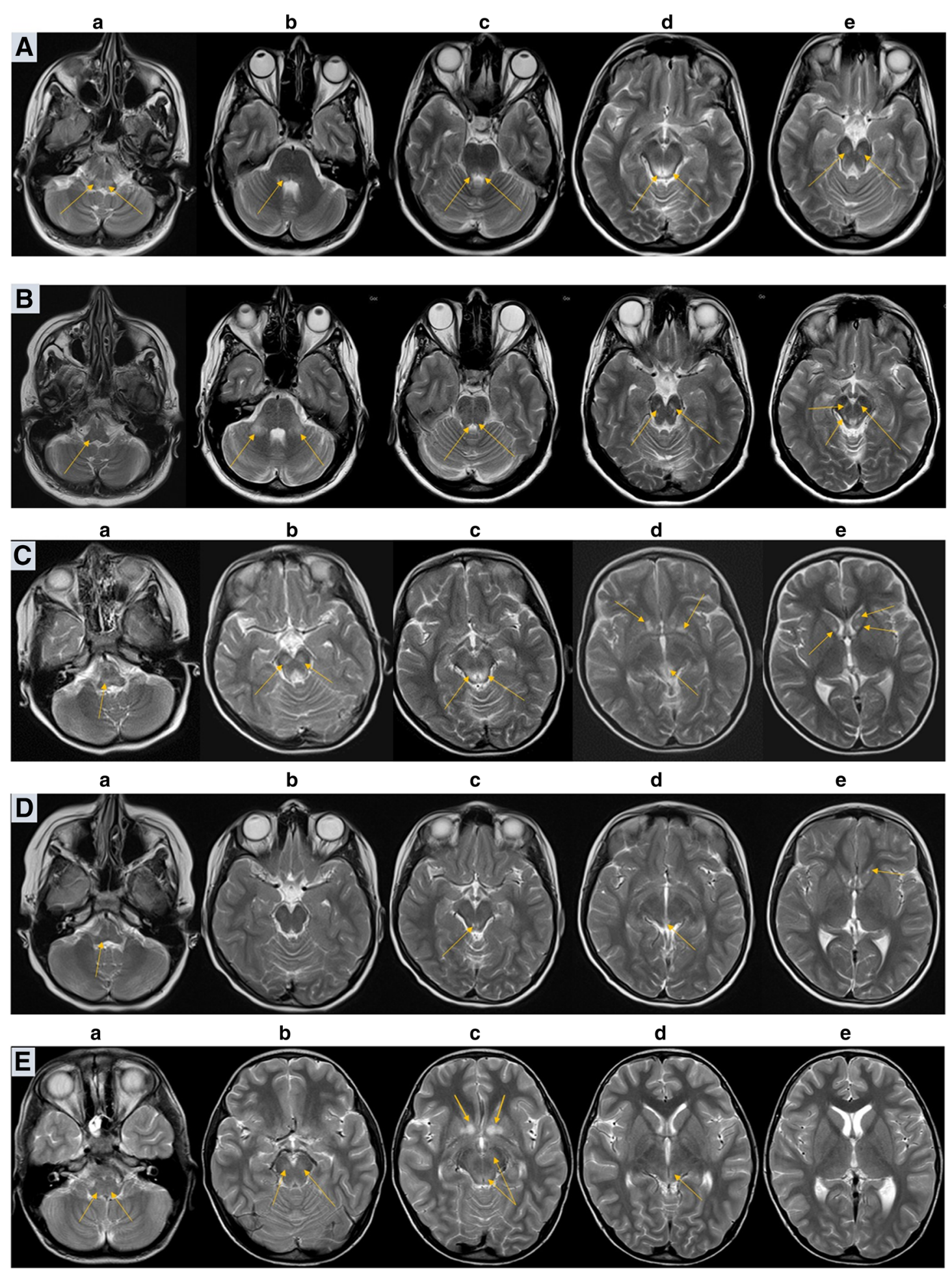

Fig. 1 Serial axial T2-weighted brain MR images of patients 1, 2, 3 and family members (FLAIR sequence) bearing m.9185T $>$ C variant of MTATP6, and autopsy findings in patient 3. Patient 1. Line A, at LS presentation at the age of 33: bilateral, symmetric hyperintensities in medulla oblongata, peripheral parts of pons and midbrain. Line B, on follow-up, 11 months later: a total regression of changes in peripheral parts of pons, presence of the previously detected lesions located in midbrain and in medulla oblongata. Greater degree of lesion demarcation. New symmetric lesions (T2-weighted hyperintensities) bilaterally within middle cerebellar peduncles. Patient 2 . Line C, at LS presentation at the age of 5 : high signal of the medulla oblongata (a), midbrain (b, c) and periaqueductal area (d). Small cystic-like lesions in the heads of the caudate nuclei (e). Line D, on the follow-up, at the age of 8: a partial but significant reduction in the severity of changes. Patient 3. Line E, at LS presentation at the age of 9: poor demarcation hyperintensities located in medulla oblongata (a), and midbrain (b, c, d); symmetric high signal lesions of the lower parts of striatum. Healthy brother of patient 3. Line F, normal MRI (a-e). Mother of patient 3. Line G, hyperintensive lesions in the posterior part of right middle cerebellar peduncle (b) and right cerebral peduncle (d), without changes in the medulla oblongata, periaqueductal region $(\mathbf{a}, \mathbf{c})$ and basal nuclei $(\mathbf{e})$ 

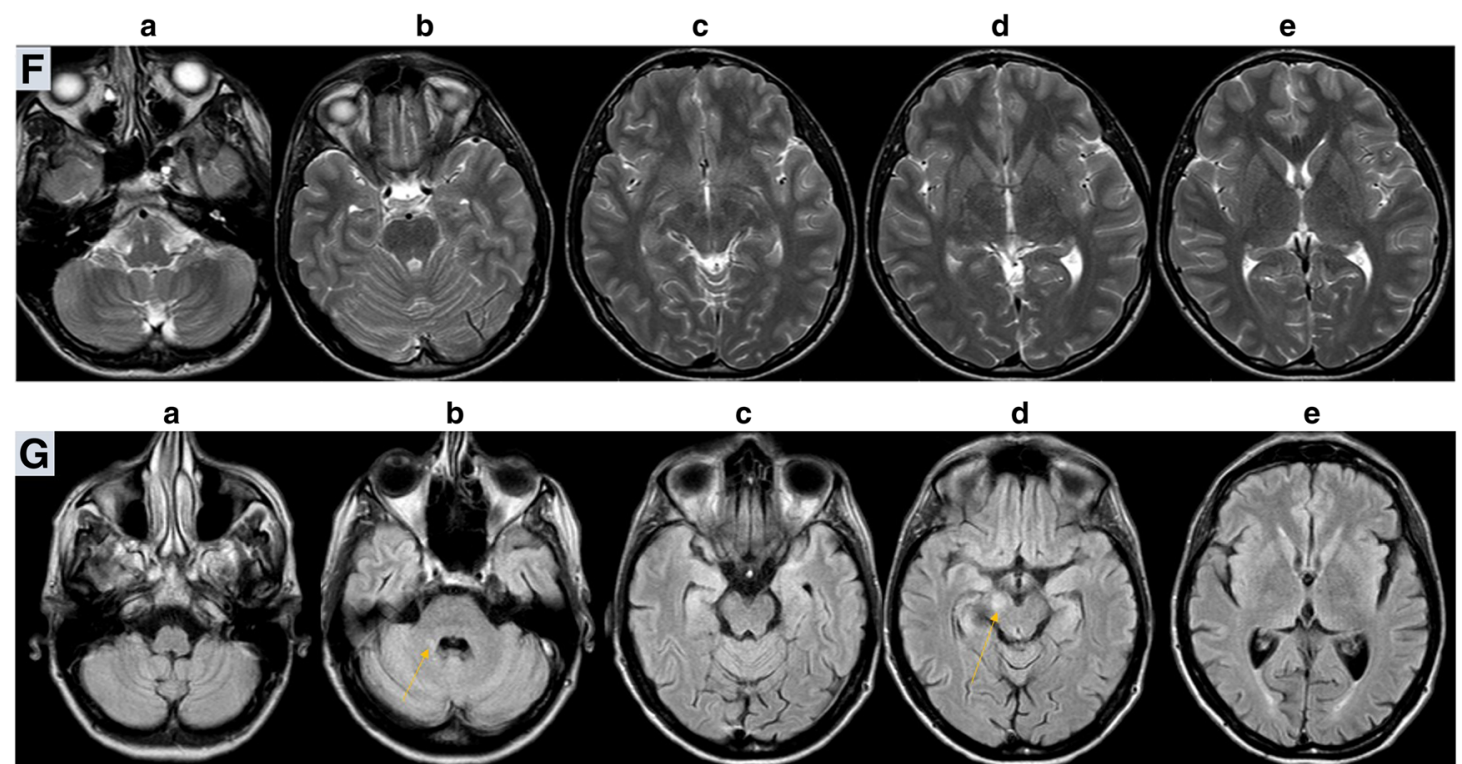

Fig. 1 (continued)

fatigability, and sleepiness. MRI revealed LS changes (Fig. 1, line E) and the boy was referred to the referential centre for mitochondrial diagnostics.

Shortly after admission, the boy collapsed suddenly and died in the episode of deterioration on the fourth day of hospitalization, within five weeks from the onset. Autopsy showed symmetrical changes characteristic for LS (proliferation of small vessels, spongiosis, damage to neurons) localized in periaqueductal areas and in the bottom of the fourth ventricle. The damage and loss of neurons were seen in dentate nucleus on both sides and to a less extent in olives nuclei. Location of brain changes on the autopsy entirely corresponded to previous MRI (Fig. 2). Accumulation of lipids in the muscle and liver as well as mosaic COX deficit in skeletal muscle were found. The MTATP6 m.9185T>C variant was identified by subsequent next generation sequencing (NGS) (Pronicka et al. 2016).

\section{Characteristics of additional $\mathrm{m.9185T}>\mathrm{C}$ carriers}

Cascade molecular study of families 1 and 2, revealed four additional $\mathrm{m} .9185 \mathrm{~T}>\mathrm{C}$ carriers. The testing was positive in all relatives included in the search, with different heteroplasmy levels in their tissues (Supplementary Table 2).

In family 1 , the m.9185T $>C$ variant was found in the mother of patient 1, aged 61, (grandmother of patient 2), and in her second 32 year-old daughter (sister of patient 1). Their heteroplasmy levels in blood and urine were $45 \%$, $55 \%$, and $15 \%$, respectively. No symptoms related to m.9185T $>C$ carriage were revealed at careful examination (Supplementary Table 2).

In family 2, two carriers of m.9185T $>C$ variant were identified (Supplementary Table 2). The older brother of patient 3, aged 18 , was completely healthy despite $>97 \%$ heteroplasmy level in blood. Brain MRI performed following the carriage detection was normal (Fig. 1, panel F). No abnormalities were revealed by extended audiological and otoneurological investigations (ABR, P300, VEMP, ENG).

The mother of two brothers from family 2 also showed m.9185T $>$ C heteroplasmy $>97 \%$ in blood and urine (Supplementary Table 2). She was healthy up to the age of 36. After death of her younger son, she developed dysarthria and depressive symptoms. At the age of 40, Alzheimer's disease (AD) was diagnosed depending on positive four generation history of AD, and presence of PSEN1 mutation previously identified in her son who died of LS (Pronicka et al. 2016). During observation, the patient developed clinical features atypical for AD (swallowing problems, seizures, spasticity, dystonia), but the brain MRI excluded LS (Fig. 1, panel G). No final conclusion could have been drawn on a possible modifying influence of m.9185T $>C$ variant on the natural history of $A D$ in this case.

\section{Measurement of blood gases}

Acid-base status was repeatedly measured during hospitalizations in arterial, capillary or venous blood of the patients, the measurements were performed according to the instructions of the equipment manufacturers. GEM Premier 3500 gasometer made by Instrumentation Laboratory USA was used for patient 1 during her stay in the intensive care unit (ICU). In other cases, the measurements were performed in local laboratories and the type of equipment used was not possible to establish.

The values of $\mathrm{pH}, \mathrm{pCO}_{2}$ and $\mathrm{pO}_{2}$ were measured directly in the apparatus. Concentration of $\mathrm{HCO}_{3}^{-}$was calculated from the received data, in relation to the atmospheric pressure and temperature. $\mathrm{HCO}_{3}^{-}$values were not checked with biochemical methods. Control values available in the literature 
Fig. 2 Brain autopsy of 9 yearold patient 3 . Basal ganglia lesions, coronal section. Gross autopsy morphology (b) shows discrete symmetric discoloration of basal ganglia located in areas corresponding to MRI (a).

Histopathological examination of affected areas reveal clearly pathological lesions, similar to that described in LS - mainly vascular capillary abundance, spongiosis, oedema (c: hematoxylin and eosin stain, original magnification 200X)

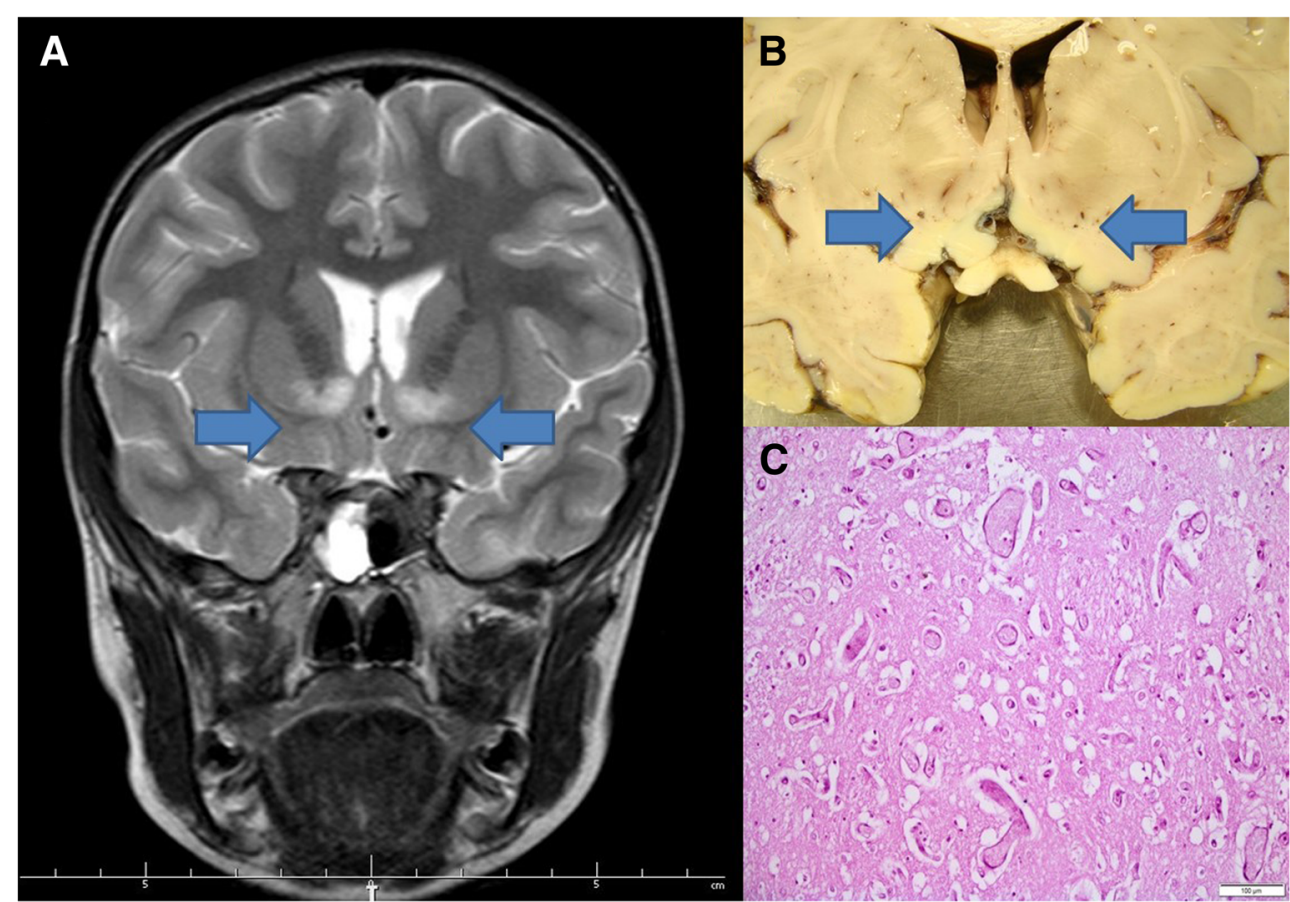

From the archive of Department of Pathology, Children's Memorial Health Institute, by courtesy of Prof. M. Pronicki. references were applied for data interpretation (Gomella and Haist 2002).

\section{Heteroplasmy analysis}

Heteroplasmy levels for the MTATP6 m.9185 T > C variant stated in this study and reported in the literature references were analysed as a whole with respect to the age of onset of the disease, symptoms and outcome.

\section{Results}

\section{Acid-base balance findings}

In patient 1 , at the beginning, acid-base data showed a substantial respiratory alkalosis, with $\mathrm{pH} 7.59$ (ref. < 7.43), $\mathrm{pCO}_{2} 11.2 \mathrm{mmHg}$ (ref. > 35), and $\mathrm{HCO}_{3}^{-} 10.4 \mathrm{mmol} / 1$ (ref. > 20), which reflected her persisting hyperpnea (Table 1, Fig. 3, panel A, point 1). At that time, high $\mathrm{pO}_{2}$ pressure of $148.4 \mathrm{mmHg}$ (ref. < 100) was found. The patient was breathing on her own and received passive oxygen therapy $\left(\mathrm{FiO}_{2}=0.35\right)$.

When the patient was placed on artificial ventilation support at intensive care unit, an uncommon pattern of acid-base equilibrium was observed, with mean $\mathrm{pH} 7.47 \pm 0.08$ (ref. 7.37-7.44), $\mathrm{pCO}_{2} 43.6 \pm 13.8 \mathrm{mmHg}$ (ref. 24-44), $\mathrm{HCO}_{3}^{-}$ $30.4 \mathrm{mmol} / \mathrm{l}$ (ref. 22-26) in arterial blood, with a shift to the "metabolic alkalosis" field on the nomogram of acid base disorders (Fig. 3, panel B, points $1-4,8,12$ ). This tendency was observed as the main feature during the entire stay at the ICU. Unfortunately, mechanisms of renal compensation were not studied in detail.

A few times, during attempts of reduction of mechanical ventilation, the retention of $\mathrm{CO}_{2}$ occurred, resulting in the transient "respiratory acidosis" status (Fig. 3, panel B, points 5,9). Episodes of excessive ventilation resulting in respiratory alkalosis pattern were noticed a few times (Fig. 3, panel B, points 6, 7, 10, 11). Only when "adequate" mechanical ventilation was restored, the arterial blood gases balance returned to the lower $\mathrm{pCO}_{2}$ range and the "metabolic alkalosis" field of the chart. During observation, at various points of artificial ventilation maintenance, a disproportionally low $\mathrm{pCO}_{2}$ (of about $1-$ $2 \mathrm{mmHg}$ ) for $\mathrm{pH} / \mathrm{HCO}_{3}^{-}$(calculated values for $\mathrm{HCO}_{3}^{-}$) could have been read out on the nomogram.

After efficient withdrawal of artificial ventilation, the pattern of "metabolic alkalosis" maintained for a few days (Fig. 3 , panel $\mathrm{B}$, points 13,14$)$. The respective values were: $7.45 \pm 0.02$ (ref. 7.37-7.44), $\mathrm{pCO}_{2} 52.1 \pm 2.1 \mathrm{mmHg}$ (ref. 24-44) and $\mathrm{HCO}_{3}^{-} 36.7 \pm 2.2 \mathrm{mmol} / \mathrm{l}$ (ref. 22-26). Without oxygen therapy, the arterial blood values of $\mathrm{pO}_{2}$ decreased to mean $84.3 \pm 11.0 \mathrm{mmHg}(n=7$, ref. 80-100).

After discharge, and during several months of clinical recovery, the status of the acid-base balance was consequently maintained at the borderline of "chronic respiratory acidosis". Respective results for venous blood were as follows: $\mathrm{pH} 7.37$, 7.35 (ref. 7.31-7.41), $\mathrm{pCO}_{2}$ 53.9, $51.6 \mathrm{mmHg}$ (ref. 40-52), 
Table 1 Acid-base parameters of three spontaneously breathing individuals at presentation of Leigh syndrome (patients 1,2 and 3)

\begin{tabular}{|c|c|c|c|c|}
\hline Parameter & Patient $1 *$ & Patient 2 & Patient 3 & $\begin{array}{l}\text { Control range } \\
\text { (Gomella and Haist 2002) }\end{array}$ \\
\hline Age & 5 years & 36 years & 9 years & \\
\hline Time & first day & first days & first two days & \\
\hline Sampling & capillary blood & ND & ND & \\
\hline $\mathrm{pH}$ & 7.59 & $7.49,7.46,7.463$ & $7.47,7.52,7.53$ & $\begin{array}{l}7.37-7.44(a) \\
7.31-7.41(v)\end{array}$ \\
\hline $\mathrm{pCO}_{2} \mathrm{mmHg}$ & 11.2 & $27.8,30.2,29$ & $27,17.1,18$ & $\begin{array}{l}36-44(a) \\
40-52(v)\end{array}$ \\
\hline $\mathrm{HCO}_{3}^{-}$(ecf) $\mathrm{mmol} / \mathrm{L}$ & 10.4 & $23.9,23.4,23.0$ & $23.6,13.5,14.6$ & $\begin{array}{l}22-26(a) \\
22-28(v)\end{array}$ \\
\hline $\mathrm{BE} \mathrm{mmol} / \mathrm{L}$ & 11.3 & $-1.9,-2.1,-2.8$ & $-2.7,-6.2,-5.1$ & $0 \pm 2(\mathrm{a}, \mathrm{v})$ \\
\hline $\mathrm{pO}_{2} \mathrm{mmHg}$ & 148.4 & 53.6 & $76,51.9,78.7$ & $\begin{array}{l}80-100(a) \\
30-50(v)\end{array}$ \\
\hline $\mathrm{O}_{2}$ saturation $\%$ & 99 & $92.9,95.8,91$ & 98 & $\begin{array}{l}>95(\mathrm{a}) \\
60-85(\mathrm{v})\end{array}$ \\
\hline Interpretation & $\begin{array}{l}\text { respiratory alkalosis, } \\
\text { partially compensated }\end{array}$ & respiratory alkalosis & $\begin{array}{l}\text { respiratory alkalosis, start } \\
\text { of metabolic compensation }\end{array}$ & - \\
\hline
\end{tabular}

*on passive oxygen therapy (nasal cannula)

Legend: $\mathrm{pCO}_{2}$ : partial pressure of carbon dioxide; $\mathrm{pO}_{2}$ : partial pressure of oxygen; $\mathrm{HCO}_{3}^{-}$: bicarbonate concentration; $\mathrm{BE}$ : base difference (deficit/ excess); ecf: extracellular fluid; (a): arterial, capillary blood; (v): venous blood; ND: not done

$\mathrm{HCO}_{3}^{-}$and $\mathrm{BE}$ values are calculated using the Henderson-Hasselbach equation

$\mathrm{HCO}_{3}^{-} 26.7,28.6 \mathrm{mmol} / 1$ (ref. 22-28), which represented a suppression of respiratory effort (a peripheral neuropathy contribution cannot be excluded). We may assume that such pattern of acid-base balance (Fig. 3, panel C) may be optimal for long term wellbeing of patient 1 .

In patient 2 , the acid base balance was assessed three times at LS presentation. The data indicated respiratory alkalosis (Table 1, Fig. 3, panel A, triangles). Recovery was achieved spontaneously; only one gasometric data is available for that period (Fig. 3, panel C, triangle).

In patient 3, hyperventilation without any signs and symptoms of upper respiratory tract infections was mentioned in the first note taken on the physical examination. Respiratory alkalosis was demonstrated three times during two first days of hospitalization (Table 1, Fig. 3, panel A, squares). It switched to metabolic acidosis just before the boy's sudden death (venous blood: $\mathrm{pH}$ 7.228, $\mathrm{pCO}_{2}$ $29.1 \mathrm{mmHg}, \mathrm{HCO}_{3}^{-} 13.5 \mathrm{mmol} / \mathrm{l}, \mathrm{BE}-14.4 \mathrm{mmol} / \mathrm{l}, \mathrm{pO}_{2}$ $72.1 \mathrm{mg} \%, \mathrm{O}_{2}$ saturation $82,2 \%$, ion gap $37.5 \mathrm{mmol} / \mathrm{l}$, ref. see Table 1).

In the healthy brother of patient 3 , asymptomatic m.9185T $>C$ carrier, the acid base balance subsequently tested three times was at the normal range (mean $\mathrm{pH} 7.385, \mathrm{pCO}_{2}$ $44.6 \mathrm{mmHg}, \mathrm{HCO}_{3}^{-} 23.2 \mathrm{mmol} / \mathrm{l}$, ion gap $5.4 \mathrm{mmol} / \mathrm{l}$ ) (Fig. 3 , panel C, star), as well as lactate concentration (mean $16.1 \mathrm{mg} / \mathrm{dl}, n=3$, ref. $<20 \mathrm{dl}$ ). No blood gases data was available for the $\mathrm{AD}$ mother of patient 3 .

\section{Heteroplasmy of $\mathbf{m . 9 1 8 5 T}>\mathrm{C}$ variant versus symptomatology}

The heteroplasmy levels found in this study and reported in the literature references are summarized in Table 2, in relation to the disease onset, studied tissue, LS occurrence and outcome. The analysed material in total includes the data of 81 individuals from 16 families aged 0.5 to 70 . Heteroplasmy level was assessed for the first time during childhood in 13 patients, during adolescence in 5 patients and at adult age in the remaining individuals (Supplementary Table 2).

Most of the patients presented the first symptoms, usually of mild severity, during childhood. The disease was slowly progressive and led to wheelchair dependence in late adulthood. Life expectancy does not seem to have been shortened. Various diagnoses including: CMT t.2, intermittent ataxia, MND, SCA, NARP, peripheral neuropathy, polyneuropathy, periodic paralysis, gait imbalance, pes cavus, were established in the reported patients (Supplementary Table 2).

LS developed in $21 \mathrm{~m} .9185 \mathrm{~T}>\mathrm{C}$ carriers (25.9\%). LS symptoms usually superimposed over earlier present neurological disturbances. LS beginning phase was acute or subacute, and disease developed in the age of 5-34, frequently in the course of infection. Asymptomatic carriage was rare $(17.3 \%)$ and mainly concerned the cases with low heteroplasmy level (Supplementary Table 2). 

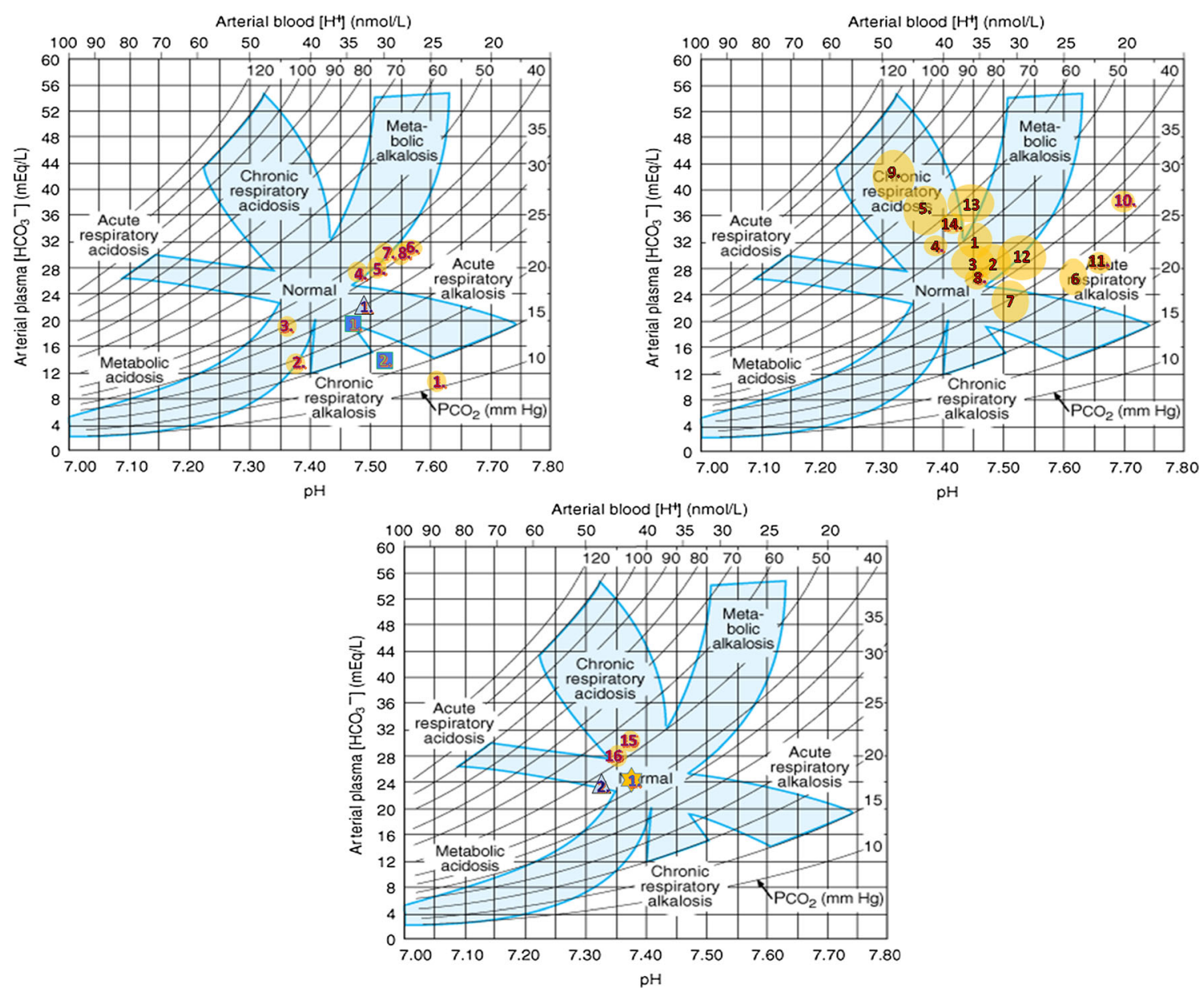

Fig. 3 Changes of acid base data observed in reported carriers of m.9185T $>C$ variant. a During spontaneous breathing in patient 1 (circles), patient 2 (triangle) and patient 3 (squares). b On artificial ventilation in patient 1 (circles). $\mathbf{c}$ During recovery of patient 1 (circles) and patient 2 (triangle), and in asymptomatic brother of patient 3 (star). Explanation of numbers inside symbols: For patient 1, one number corresponds to many tests performed during the entire observation, whose

\section{Comments and discussion}

In three patients with LS of late onset (5-33 years), bearing MTATP6 m.9185T >C variant, we showed (on empirical basis) that hyperventilation coincided with LS onset in all of them. No such coexistence was reported previously, with one exception (Castagna et al. 2007). However, many other factors, coexisting with clinical deterioration of m.9185T $>$ C carriers were reported. The set includes febrile viral illness (Castagna et al. 2007, Saneto and Singh 2010, Pitceathly et al. 2012), summer heat (Saneto and Singh 2010), panic attacks (Childs et al. 2007), prolonged sitting (Auré et al. 2013) (Supplementary Table 3).

Excessive respiration effort (hyperventilation) in any case causes changes in partial blood gases pressure (p). If hyperventilation persists, it leads to a disproportionally low $\mathrm{pCO}_{2}$ (hypocapnia). Blood $\mathrm{pO}_{2}$ independently adjusts to the composition of inspiratory air. We noticed such changes in blood results were situated in the same position of the nomogram; 53 measurements were included together and clustered/gathered in circles 1-16 (Supplementary Table 1, column 1). For other three individuals (triangles, squares, star), the numbers show order in time of measurements. Copyright/licensed by McGraw-Hill Education adopted from Gomella and Haist (2002)

gases in reported patients at onset of LS, with low $\mathrm{pCO}_{2}$ in patients 1,2 and 3 , and relatively high $\mathrm{pO}_{2}$, especially in patient 1, during passive oxygen therapy (Table 1). Occurrence of hyperventilation was reflected by acid-base pattern, which shifted to the "respiratory alkalosis" field on the nomogram for acid-base disorders (Fig. 3, panel A). The alkalosis was initially acute (non-compensated, with blood $\mathrm{pH}$ maximum of 7.59 (ref. < 7.43) and later compensated, due to the start of renal $\mathrm{HCO}_{3}^{-}$loss. Lowering of $\mathrm{HCO}_{3}^{-}$was always preceded by lowering of $\mathrm{pCO}_{2}$.

Our study confirms that the course of m.9185T $>$ C related LS differs markedly from the majority of other LS types, in which the onset is early, and outcome irreversibly poor. The m.9185T >C-related LS tends to recover, at least partially. The natural history of the condition in some respect resembles a common m.8993 T > C substitution in MTATP6 (Craig et al. 2007). Two out of three reported LS patients with m.9185T $>C$ variant recovered partially (patient 1 ) or almost completely 
Table 2 Clinical characteristics of heteroplasmy levels in 81 individuals with MTATP6 m.9185T $>$ C variant

\begin{tabular}{lllll}
\hline & Mean $+/-$ SD & Median value & Range & $\begin{array}{l}\text { Number } \\
\text { of data* }\end{array}$ \\
\hline Onset of symptoms, years & $23.6 \pm 19.3$ & 18 & $0.5-80$ & 56 \\
Leigh syndrome, years & $12.1 \pm 9.5$ & 9 & $0.5-34$ & 18 \\
Last seen/death, years & $29.3 \pm 18.2$ & 24 & $7-79$ & 33 \\
Age of death, years & $15.9 \pm 13.6$ & 10 & $0.5-48$ & 11 \\
Heteroplasmy study, years & $18.1 \pm 14.6$ & 16 & $7-61$ & 27 \\
Blood, \% & $85.5 \pm 21.7$ & 97 & $15-100$ & 44 \\
Urine, \% & $83.4 \pm 21.8$ & 91 & $15-100$ & 17 \\
Buccal cells, \% & $93.6 \pm 9.2$ & 98.5 & $67-100$ & 14 \\
Hair, \% & $85.9 \pm 17.8$ & 91.5 & $35-100$ & 14 \\
Fibroblasts, \% & $94.1 \pm 4.9$ & 91 & $90-100$ & 7 \\
Muscle, \% & $95.9 \pm 7$ & 99 & $73-100$ & 18 \\
All tissue minimal value, \% & $86.9 \pm 21$ & 97 & $15-100$ & 75 \\
All tissue maximal value, \% & $90.3 \pm 19.6$ & 100 & $15-100$ & 75 \\
\hline
\end{tabular}

Literature data. (Moslemi et al. 2005, Castagna et al. 2007, Childs et al. 2007, Saneto and Singh 2010, Pitceathly et al. 2012, Brum et al. 2014, Danqun et al. 2015 abstr., Pronicka et al. 2016). More details: Supplementary Table 2

*in 28 patients heteroplasmy was measured in DNA specimens isolated from more than one tissue (patient 2). The recovery of $\mathrm{m} .9185 \mathrm{~T}>\mathrm{C}$-related LS was previously reported at least in nine patients (Moslemi et al. 2005; Childs et al. 2007; Saneto and Singh 2010) (Supplementary Table 3).

Analysis of changes in acid-base parameters during the course of LS in surviving patients 1 and 2 shows that their recovery coexisted with the higher $\mathrm{pCO}_{2}$ ("hypercapnia") and lower $\mathrm{pO}_{2}$ ("hypoxia") values (Fig. 3, panel C), in contrast to the deterioration period (Fig. 3, panel A). Surprisingly, this data points to a relatively low respiratory drive on the recovery. It may be speculated that the m.9185T $>C$ carriers do not require increased oxygen concentrations, if compared with healthy controls, and that higher $\mathrm{CO}_{2}$ and lower $\mathrm{O}_{2}$ supplies may be beneficial for them.

The above data is in accordance with our "hypocapnic hypothesis" of LS (Pronicka 2017). The hypothesis assumes that hypocapnia (low $\mathrm{pCO}_{2}$ ) leads to intracellular alkalization (high $\mathrm{pH}$ ) of brain cells. Inside mitochondria, the signal of high $\mathrm{pH} /$ low bicarbonate ion $\left(\mathrm{HCO}_{3}^{-}\right)$is transmitted by soluble adenyl cyclase (sAC) through cAMP dependent manner (Buck and Levin 2014), and results in modification of activities of proteins involved in OXPHOS, apoptosis and other relevant processes. It can initiate brain lesions (necrosis, apoptosis, hypervascularity) in MTATP6 mutated cells (astrocytes?) residing at the LS area of the brain.

The hypocapnic hypothesis of LS, and our findings that the patients with m.9185C > T-related LS showed clinical improvement in parallel with higher $\mathrm{pCO}_{2}$ and lower $\mathrm{pO}_{2}$, may also help to understand the basis of beneficial effect of hypoxia in animal model of LS (Jain et al. 2016). It has been shown that chronic hypoxia (11\% vs $34 \%$ ) in surrounding atmosphere leads to a marked improvement in survival, body weight, body temperature, behavior, neuropathology and disease biomarkers in the NDUFV4 mutated mouse model (Jain et al. 2016).

The analysis of the patients included in the study and those previously reported in the literature (in total number of 81), extends our knowledge on natural history of carriage of m.9185T $>\mathrm{C}$ variant in MTATP6. It shows that the $\mathrm{m} .9185 \mathrm{~T}>\mathrm{C}$ carriage alone does not prejudge the occurrence of disease symptoms, including LS. About $18 \%$ of carriers may remain healthy throughout life, particularly if the m.9185T $>C$ heteroplasmy is low. However, in most of the individuals, discrete anomalies of development appear during early childhood (Supplementary Table 3). Later in life, the carriers developed neuropathic symptoms recognized as CMT1 (Pitceathly et al. 2012), periodic paralysis (Auré et al. 2013), peripheral neuropathy and others.

LS occurred in about one quarter of carriers, including our patients 1, 2 and 3, always of the late-onset type and at the age difficult to predict. It seems that there are three intervals of increased risk of LS: 5-9 years of age, 16-19, and above 30. The onset was acute or subacute (Moslemi et al. 2005, Pitceathly et al. 2012, Saneto and Singh 2010, Castagna et al. 2007, Auré et al. 2013, Brum et al. 2014, Pfeffer et al. 2012, Childs et al. 2007, Danqun et al. 2015, this study). At present, it is difficult to conclude whether the m.9185T $>$ C variant on its own may be the "isolated" cause of LS.

It is known of course that high level of heteroplasmy constitutes an important risk factor for appearance of symptoms (Table 2). However, even $100 \%$ of mutated mtDNA does not prejudge the disease onset like in the 18 year-old 
asymptomatic brother of patient 3 . We suppose that extra harmful factors have to occur (as discussed above hyperventilation evoked by a stressful event) to induce a chronic neuropathy or LS in $\mathrm{m} .9185 \mathrm{~T}>\mathrm{C}$ carriers.

Summing up, at present there is no basis to unambiguously answer the question whether being an m.9185T $>\mathrm{C}$ carrier is equal with having a mitochondrial disease (with a delayed onset). To extend our knowledge of the natural history of the $\mathrm{m} .9185 \mathrm{~T}>\mathrm{C}$ carriage, the population prevalence and prospective observations of asymptomatic carriers throughout their lives are desired.

Better understanding of the natural history of m.9185T $>C$ carriage, as well as pathomechanism of LS development, will allow to find out if there is any way to prevent m.9185T>C related symptoms in asymptomatic carriers, as well as occurrence of LS in patients with neuropathy associated with this MTATP6 variant.

As long as it is not fully explained, basing on our own observations, we suggest to counteract hyperventilation (hypocapnia) and carefully dose oxygen in $\mathrm{m} .9185 \mathrm{~T}>\mathrm{C}$ carriers and the patients with $\mathrm{m} .9185 \mathrm{~T}>\mathrm{C}$ related LS.

Acknowledgements We express our gratitude to both families for participation in the study and for tremendous help in gathering medical documentation from many regional hospitals, academic centers and national institutes, which participated in the diagnostics over many years.

The work was partially funded by the Children's Memorial Health Institute grants: S136/13, S238/16, and S145/16.

\section{Compliance with ethical standards}

Ethical approval All procedures performed in the study were in accordance with the ethical standards of the CMHI bioethical committee and with the 1964 Helsinki declaration and its later amendments or comparable ethical standards.

Informed consent was obtained from all individual participants included in the study.

Conflict of interest The authors declare that they have no conflict of interest.

Open Access This article is distributed under the terms of the Creative Commons Attribution 4.0 International License (http:// creativecommons.org/licenses/by/4.0/), which permits unrestricted use, distribution, and reproduction in any medium, provided you give appropriate credit to the original author(s) and the source, provide a link to the Creative Commons license, and indicate if changes were made.

\section{References}

Auré K, Dubourg O, Jardel C, Clarysse L, Sternberg D, Fournier E, Laforêt P, Streichenberger N, Petiot P, Gervais-Bernard H, Vial C, Bedat-Millet AL, Drouin-Garraud V, Bouillaud F, Vandier C, Fontaine B, Lombès A (2013) Episodic weakness due to mitochondrial DNA MT-ATP6/8 mutations. Neurology 81:1810-1818. https://doi.org/10.1212/01.wnl.0000436067.43384.0b
Brum M, Semedo C, Guerreiro R, Pinto Marques J (2014) Motor neuron syndrome as a new phenotypic manifestation of mutation $9185 \mathrm{~T}>\mathrm{C}$ in gene MTATP6. Case Rep Neurol Med. https://doi.org/10.1155/2014/701761

Buck J, Levin LR (2014) The role of soluble adenylyl cyclase in health and disease. Biochim Biophys Acta 1842:2533-2534. https://doi. org/10.1016/j.bbadis.2014.09.009

Castagna AE, Addis J, McInnes RR, Clarke JT, Ashby P, Blaser S, Robinson BH (2007) Late onset Leigh syndrome and ataxia due to a $\mathrm{T}$ to $\mathrm{C}$ mutation at bp 9,185 of mitochondrial DNA. Am J Med Genet A 143A:808-816

Childs AM, Hutchin T, Pysden K, Highet L, Bamford J, Livingston J, Crow YJ (2007) Variable phenotype including Leigh syndrome with a 9185T $>$ C mutation in the MTATP6 gene. Neuropediatrics 38:313316. https://doi.org/10.1055/s-2008-1065355

Craig K, Elliott HR, Keers SM, Lambert C, Pyle A, Graves TD, Woodward C, Sweeney MG, Davis MB, Hanna MG, Chinnery PF (2007) Episodic ataxia and hemiplegia caused by the $8993 \mathrm{TC}$ mitochondrial DNA mutation. J Med Genet 44:797-799. https://doi.org/ 10.1136/jmg.2007.052902

Danqun J, Jie D, Wenjia T, Kefei H (2015) Clinical characteristics and genetic analysis of two cases with Leigh syndrome with acute pulmonary hemorrhage as predominant manifestation. Zhonghua Er Ke Za Zhi 53(4):290-295 Abstract [Article in Chinese]

Gomella LG, Haist SA (eds) (2002) Clinician's Pocket Reference. Ninth Edition, McGraw-Hill Medical Edical Publishing Division, New York

Jain IH, Zazzeron L, Goli R, Alexa K, Schatzman-Bone S, Dhillon H, Goldberger O, Peng J, Shalem O, Sanjana NE, Zhang F, Goessling W, Zapol WM, Mootha WK (2016) Hypoxia as a therapy for mitochondrial disease. Science 352(6281):54-61

Lake NJ, Compton AG, Rahman S, Thorburn DR (2016) Leigh syndrome: one disorder, more than 75 monogenic causes. Ann Neurol 79:190-203. https://doi.org/10.1002/ana.24551

Moslemi AR, Darin N, Tulinius M, Oldfors A, Holme E (2005) Two new mutations in theMTATP6 gene associated with Leigh syndrome. Neuropediatrics 36:314-318

Pfeffer G, Blakely EL, Alston CL, Hassani A, Boggild M, Horvath R, Samuels DC, Taylor RW, Chinnery PF (2012) Adult-onset spinocerebellar ataxia syndromes due to MTATP6 mutations. J Neurol Neurosurg Psychiatry 83:883-886. https://doi.org/10.1136/ jnnp-2012-302568

Pitceathly RD, Murphy SM, Cottenie E, Chalasani A, Sweeney MG, Woodward C, Mudanohwo EE, Hargreaves I, Heales S, Land J, Holton JL, Houlden H, Blake J, Champion M, Flinter F, Robb SA, Page R, Rose M, Palace J, Crowe C, Longman C, Lunn MP, Rahman S, Reilly MM, Hanna MG (2012) Genetic dysfunction of MT-ATP6 causes axonal Charcot-Marie-tooth disease. Neurology 79:1145-1154. https://doi.org/10.1212/WNL.0b013e3182698d8d

Pronicka E (2017) Hypocapnic hypothesis of Leigh disease. Med Hypotheses 101:23-27. https://doi.org/10.1016/j.mehy.2017.01.01

Pronicka E, Halikowski B (1984) Metabolic acidosis versus a compensation of respiratory alkalosis in four children with Leigh's disease. J Inherit Metab Dis 7(suppl 2):113-114

Pronicka E, Piekutowska-Abramczuk D, Ciara E, Trubicka J, Rokicki D, Karkucińska-Więckowska A, Pajdowska M, Jurkiewicz E, Halat P, Kosińska J, Pollak A, Rydzanicz M, Stawinski P, Pronicki M, Krajewska-Walasek M, Płoski R (2016) New perspective in diagnostics of mitochondrial disorders: two years' experience with whole-exome sequencing at a national paediatric centre. J Transl Med 14:174. https://doi.org/ 10.1186/s12967-016-0930

Saneto RP, Singh KK (2010) Illness-induced exacerbation of Leigh syndrome in a patient with the MTATP6 mutation, m.9185 T>C. Mitochondrion 10:567-572 